\title{
Significance of long-term surveillance for branch-duct intraductal papillary mucinous neoplasms from the perspective of molecular pathological epidemiology
}

\author{
Keisuke Kosumi ${ }^{1,2}$, Hiromitsu Hayashi ${ }^{2}$, Hideo Baba ${ }^{2}$ \\ ${ }^{1}$ Department of Surgery, National Hospital Organization Kumamoto Medical Center, Chuo-ku, Kumamoto, Japan; ${ }^{2}$ Department of \\ Gastroenterological Surgery, Graduate School of Medical Sciences, Kumamoto University, Chuo-ku, Kumamoto, Japan \\ Correspondence to: Hideo Baba, MD, PhD, FACS. Department of Gastroenterological Surgery, Graduate School of Medical Sciences, Kumamoto \\ University, 1-1-1 Honjo, Chuo-ku, Kumamoto 860-8556, Japan. Email: hdobaba@kumamoto-u.ac.jp. \\ Provenance and Peer Review: This article was a free submission to the journal. The article did not undergo external peer review.
}

Submitted Mar 05, 2020. Accepted for publication Jun 19, 2020.

doi: $10.21037 /$ atm-20-2206

View this article at: http://dx.doi.org/10.21037/atm-20-2206

With considerable interest, we read the article published by Oyama et al., who investigated the significance of longterm follow-up of patients with branch-duct intraductal papillary mucinous neoplasms (IPMNs) (1). The American Gastroenterological Association guidelines recommend discontinuing surveillance of asymptomatic pancreatic cysts with no or minimal change during the initial 5-year observation (2). The significance of long-term follow-up of patients with branch-duct IPMNs has not been fully evaluated in large studies. In an eager attempt to clarify the necessity of long-term follow-up, a large long-term study of patients with branch-duct IPMNs was reported by Oyama et al. in Gastroenterology. Oyama and colleagues analyzed incidences of IPMN-derived carcinoma and concomitant pancreatic ductal adenocarcinoma (PDAC) in over 1,400 consecutive patients with branch-duct IPMN diagnosed during over 20 years. During 9,231 person-years of followup, they provided a diagnosis of pancreatic carcinoma for 68 patients (IPMN-derived carcinoma for 38 and concomitant PDAC for 30). The cumulative incidence rates of pancreatic carcinoma overall slightly increased with time. They also evaluated potential risk factors for pancreatic carcinoma overall and specific types of carcinomas. The size of the IPMN and the diameter of the main pancreatic duct (MPD) had association with incidence of IPMN-derived carcinoma, but not with incidence of concomitant PDAC $\left(\mathrm{P}_{\text {heterogeneity }}\right.$ $=0.004$ and 0.061 , respectively). Their findings may support consecutive surveillance of patients with branch-duct IPMNs over 5 years as long as they remain fit for surgery, and suggest distinct carcinogenic processes between IPMNderived and de novo carcinomas.

The present study by a Japanese research group provides evidence supporting long-term surveillance of patients with branch-duct IPMNs beyond 5 years. Utilizing a large patient cohort, the researchers demonstrated an almost linear increase in the risk of pancreatic cancer during the follow-up period (up to 15 years) in this population. In the analysis limited to small cysts $(<15 \mathrm{~mm})$, they observed a 7-fold higher risk of pancreatic carcinoma compared to the general Japanese population. As a result of their intense surveillance, pancreatic carcinomas identified in this study were non-metastatic in $89 \%$ patients. Taking high mortality of pancreatic cancer into account, we agree with the researchers that a further investigation is required to justify the discontinuation of surveillance of branch-duct IPMNs at 5 years.

Of note, the current study represented a molecular pathological epidemiology (MPE) study of pancreatic cancer. Evidence from genetic research suggests that branch-duct IPMNs is driven by two major pathways $(3,4)$. While main genetic alterations driving PDAC have been mutations or deletions in KRAS, CDKN2A (p16), TP53 (p53), and SMAD4, GNAS mutation is detected specifically in $41-66 \%$ of IPMN lesions. MPE is a transdisciplinary integrative research field, which has been derived from efforts to integrate the methodology of molecular pathology into population-based epidemiologic research $(5,6)$. Beyond the conventional epidemiological approach, MPE research 
attempts to explore differential associations of an exposure with several distinct subtypes classified by molecular or pathological features of the disease (7). Through this approach, MPE research cannot only provide novel insights into interactions among environment, tumor, and host, but also open new research frontiers in fields of various cancers including colorectal cancer (8). Given that pancreatic carcinomas are a heterogeneous collection of neoplasms arising in the pancreas, there should be ample opportunities for MPE research on incidence and consequence of pancreatic cancer. Here, Oyama et al. analyzed mutation statuses of KRAS and GNAS for the carcinoma and matched IPMN epithelium, and differentiated IPMN-derived carcinoma and carcinoma concomitantly arising in the pancreas. They examined the heterogeneity in associations of clinical and tumor parameters with incidences of carcinoma subtypes, and successfully found different risk factor profiles for those subtypes. Namely, characteristics of IPMN (the diameter of the MPD, etc.) were associated with incidence of IPMN-derived carcinoma, but not with concomitant PDAC. For concomitant PDAC, older age was the sole predictive factor for its incidence. Therefore, patients with small cysts may keep caring a substantial risk of concomitant PDAC. We commend the authors to provide us with these data, which would refine our surveillance programs of branch-duct IPMNs.

In summary, the study by Oyama et al. does not only support extended follow-up for patients with branch-duct IPMN, but also serve an illustrative MPE study of incidence of pancreatic cancer. We argue that MPE can establish a basis for individualized prevention and treatment strategies of pancreatic cancer (9-11). Further integrated analyses of environmental factors such as lifestyle factors, tumor, host immunity, and microbiome based on MPE research (microbialMPE and immunology-MPE) can eventually play critical roles in providing rationales and discovering insights into precision medicine, therapy, and prevention for pancreatic cancer.

\section{Acknowledgments}

Funding: This work was supported in part by a Grant-inAid for Scientific Research from the Japan Society for the Promotion of Science (19K16750 to KK). The funders had no role in submission or preparation of the manuscript.

\section{Footnote}

Conflicts of Interest: All authors have completed the ICMJE uniform disclosure form (available at http://dx.doi. org/10.21037/atm-20-2206). KK reports grants from Japan Society for the Promotion of Science, during the conduct of the study. The other authors have no conflicts of interest to declare.

Ethical Statement: The authors are accountable for all aspects of the work in ensuring questions related to the accuracy or integrity of any part of the work are appropriately investigated and resolved.

Open Access Statement: This is an Open Access article distributed in accordance with the Creative Commons Attribution-NonCommercial-NoDerivs 4.0 International License (CC BY-NC-ND 4.0), which permits the noncommercial replication and distribution of the article with the strict proviso that no changes or edits are made and the original work is properly cited (including links to both the formal publication through the relevant DOI and the license). See: https://creativecommons.org/licenses/by-nc-nd/4.0/.

\section{References}

1. Oyama H, Tada M, Takagi K, et al. Long-term Risk of Malignancy in Branch-Duct Intraductal Papillary Mucinous Neoplasms. Gastroenterology 2020;158:226-37.e5.

2. Vege SS, Ziring B, Jain R, et al. American gastroenterological association institute guideline on the diagnosis and management of asymptomatic neoplastic pancreatic cysts. Gastroenterology 2015;148:819-22; quiz e12-3.

3. Patra KC, Bardeesy N, Mizukami Y. Diversity of Precursor Lesions For Pancreatic Cancer: The Genetics and Biology of Intraductal Papillary Mucinous Neoplasm. Clin Transl Gastroenterol 2017;8:e86.

4. Omori Y, Ono Y, Tanino M, et al. Pathways of Progression From Intraductal Papillary Mucinous Neoplasm to Pancreatic Ductal Adenocarcinoma Based on Molecular Features. Gastroenterology 2019;156:647-61.e2 .

5. Campbell PT, Ambrosone CB, Nishihara R, et al. Proceedings of the fourth international molecular pathological epidemiology (MPE) meeting. Cancer Causes Control 2019;30:799-811.

6. Phipps AI, Alwers E, Harrison T, et al. Association Between Molecular Subtypes of Colorectal Tumors and Patient Survival, Based on Pooled Analysis of 7 International Studies. Gastroenterology 2020;158:2158-68.e4.

7. He X, Wu K, Ogino S, et al. Association Between Risk Factors for Colorectal Cancer and Risk of Serrated 
Polyps and Conventional Adenomas. Gastroenterology 2018;155:355-73.e18.

8. Kosumi K, Hamada T, Zhang S, et al. Prognostic association of PTGS2 (COX-2) over-expression according to BRAF mutation status in colorectal cancer: Results from two prospective cohorts and CALGB 89803 (Alliance) trial. Eur J Cancer 2019;111:82-93.

9. Ogino S, Giannakis M. Immunoscore for (colorectal) cancer precision medicine. Lancet 2018;391:2084-6.

10. Ogino S, Nowak JA, Hamada T, et al. Integrative analysis of exogenous, endogenous, tumour and immune factors for precision medicine. Gut 2018;67:1168-80.

11. Ogino S, Nowak JA, Hamada T, et al. Insights into Pathogenic Interactions Among Environment, Host, and Tumor at the Crossroads of Molecular Pathology and Epidemiology. Annu Rev Pathol 2019;14:83-103.
Cite this article as: Kosumi $\mathrm{K}$, Hayashi $\mathrm{H}$, Baba $\mathrm{H}$. Significance of long-term surveillance for branch-duct intraductal papillary mucinous neoplasms from the perspective of molecular pathological epidemiology. Ann Transl Med 2020;8(15):977. doi: 10.21037/atm-20-2206 